\title{
The psychosocial impact of the smile arc and buccal corridor in young people in southern Peru
}

\section{El impacto psicosocial del arco de sonrisa y corredor bucal en jóvenes del sur de Perú}

\author{
Cinthia Coronel-Quenallata ${ }^{1}$, Sively L. Mercado-Mamani* ${ }^{2}$, Jorge Mercado-Portal ${ }^{3}$, Luz Mamani-Cahuata ${ }^{3}$, \\ ${ }^{1}$ Odontóloga de consulta particular. \\ ${ }^{2}$ Universidad Nacional de San Agustín Arequipa. ${ }^{3}$ Universidad Nacional del Altiplano. Puno, Perú. \\ *goty20@ hotmail.com
}

\begin{abstract}
Resumen
Objetivo: Determinar el impacto psicosocial del arco de la sonrisa y el corredor bucal en estudiantes de 18 a 32 años, de la Facultad de Odontología, de la Universidad Andina Nestor Cáceres Velásquez. Materiales y Método: Se realizó un estudio descriptivo, cualitativo, transversal; la muestra consistió en 130 individuos de 18 a 32 años. Se utilizó el Cuestionario de Impacto Psicosocial de Estética Dental (PIDAQ) y las fotografías de la sonrisa se tomaron en posición natural. Se evaluó el arco de la sonrisa y el corredor bucal, y se determinó el grado de satisfacción de la sonrisa en cada género.Resultados: Se encontró una relación estadísticamente significativa, donde la satisfacción de la sonrisa fue pobre en un $61,1 \%$, mientras que un 63,6\% fue regular, siendo el más frecuente. El 30,3\% fue bueno, obteniendo una relación estadísticamente significativa en el género femenino.Conclusión: en línea el vídeo que mejor se adapte a su documento.
\end{abstract}

Palabras clave: Impacto psicosocial, arco de la sonrisa, corredor bucal.

\begin{abstract}
Objective: To determine the psychosocial impact of the smile arc and buccal corridor in students 18 to 32 years of age, from the Faculty of Dentistry, of the University Andina Nestor Caceres Velasquez. Materials and Methods: A descriptive, qualitative, cross-sectional study was carried out; the sample consisted of 130 individuals, aged 18 to 32 years. The Dental Aesthetic Psychosocial Impact Questionnaire (PIDAQ) was used, and the photographs of the smile were taken in a natural position. The smile arc and buccal corridor were evaluated, and the degree of smile satisfaction in each gender was determined. Results:A statistically significant relationship was found, where the patients' satisfaction with their smile was poor in $61.1 \%$, meanwhile $63.6 \%$ was regular, being the most frequent. $30.3 \%$ was good, obtaining a statistically significant relation in the female gender Conclusion:. The psychosocial impact of the smile arc and the vestibular corridor on aesthetic preference is more relevant in the female gender.
\end{abstract}

Key words: Psychosocial impact, smile arc, buccal corridor.

\section{INTRODUCTION}

Currently, the social impact of the smile and how it influences the quality of life of people is increasing and being more investigated. The psychosocial impact of dental aesthetics is not associated with degrees of defective occlusion, oral quality of life measures, and people's selfimage. ${ }^{1}$

Malocclusions are defined as problems of muscleskeletal growth during childhood and adolescence, which can cause aesthetic teeth and face problems, as well as alterations in mastication, phonation and occlusion. ${ }^{1} \mathrm{~A}$ dental appearance that deviates from general standards may stigmatize, prevent peer acceptance, foster a negative stereotype, and have an adverse effect on patient selfesteem. Therefore, a dental appearance can reduce the opportunities to access occupations where image is important, so malocclusion can interpose in the aspirations and job opportunities of an affected individual. From this assumption, the importance of the diagnosis of malocclusion, in the context of oral health and the quality of life of individuals, can be deduced. ${ }^{1}$

Defective occlusions represent an important global health problem. ${ }^{2}$ Several epidemiological studies conducted in various countries, mainly in Northern Europe and North America, have reported that this oral disorder is very 
prevalent. ${ }^{2}$ Defective occlusion not only affects function and appearance, but also produces economic, social and psychological effects. ${ }^{4,5}$ In people with minor defective dental occlusion, there is insufficient evidence to suggest that orthodontic treatment improves dental health and function. Treatment is often justified by the potential enhancement of psychological and social well-being, through improvements in appearance. ${ }^{6}$ Traditional indexes, such as the Dental Aesthetic Index (DAI) and the Orthodontic Treatment Needs Index (IOTN), assess the aesthetic and anatomical components of defective occlusion, but do not provide any information on how defective occlusion affects self-image and the quality of life of patients. ${ }^{6}$ Well-aligned teeth and a pleasant smile are associated with a positive status at all social levels, while irregular or protruding teeth have negative connotations. ${ }^{7}$ Children who are going to start an orthodontic treatment generally expect to improve their social and psychological well-being. ${ }^{8}$

There is no doubt that the social responses conditioned by the appearance of the face and smile can significantly influence the complete vital adaptation of an individual, which encompasses the concept of ünfavorable occlusionïn a broader and more important context. If an individual's teeth constantly affect relationships with others, dental damage cannot be considered trivial. Available data suggests that, in a population with limited income, partial and early treatment can improve (rather than completely correct) the more obvious malocclusions and produce benefits in terms of psychosocial aspects. ${ }^{9}$

Interestingly, the psychic rejection caused by facial or dental alteration is not directly proportional to the anatomical severity of the problem. An individual with highly altered dental characteristics can expect a negative response. Whereas, an individual with a seemingly less serious problem (i.e. protruding chin or irregular incisors) is sometimes treated differently because it seems easier to accept a defect if the rest of the people respond or accept it positively. Unpredictable responses produce anxiety and can have strong negative effects. The impact of a physical defect on an individual will greatly depend on their self-esteem. ${ }^{10}$

In the first approach, for a general facial aesthetics evaluation, there are two essential elements: the smile design and facial mid line. When assessing the attractiveness of a person's smile, it is considered prudent to observe the face as a whole entity, rather than isolating the elements of the observation into different parts. The aesthetic preference, by which each person is inclined to, varies from person to person, since their environment and personal development play an important role in their opinions. A professional or student opts for a different opinion, due to studies and research that influence their perspective of aesthetic and harmonic smiles. Therefore, this investigation proposed to evaluate the psychosocial impact of the smile arc and buccal corridor, on students aged 18 to 32 years, at the Faculty of Dentistry of the "Universidad Andina Néstor Cáceres Velasquez", Juliaca-Peru.

\section{MATERIAL AND METHODS}

The present investigation is a descriptive, prospective and cross-sectional study. The sample consisted of 130 students, 18 - 32 years old, from the Faculty of Dentistry of the Andina Néstor Cáceres Velásquez University, in the city of Juliaca-Peru. The formula was applied to estimate a proportion; the data was obtained from a previous pilot test carried out, aiming to train and calibrate the researchers and standardized procedures. Simple random sampling was performed, and the selection criteria were: students without orthodontic treatment, who had all of their anterior teeth, no anterior bridge or crown, presented no systemic diseases, and attended the University on a regular basis.

To begin the data collection, there were different coordination actions carried out, requesting the approval and authorization of management of the Faculty of Dentistry of the UANCV, Juliaca-Peru. For the pilot study, each student received a detailed explanation of the study, and an informed consent was given. An attached questionnaire in the annex section (PIDAQ), photographs, and an informed consent were used to register the patients. For its execution, the PIDAQ questionnaire was completed, where the psychosocial impact of the dental aesthetics of each of the students was evaluated, followed by photographs of each student's smile zone; where the smile arc and buccal corridor with a suitable posture for photography were evaluated. For the statistical analysis of the data, a Sony Vaio Laptop with an Intel Core 2 Duo process or was used, and for the statistical analysis, the IBM SPSS 22.0 ® software for Windows 8 program was used. In the present study, a significance level of 0.05 , corresponding to a $95 \%$ confidence interval, was set. The percentages and frequencies, the mean, and the standard deviation of the qualitative variables were obtained. To establish the association, a statistical Mann-Whitney $U$ test was performed; if the $p$ value is less than 0.05; a significant difference was assumed. Finally, the Pearson correlation test was used to establish the relationship between degree of perception and aesthetic preference.(Tabla 4)

\section{RESULTS}

In the present study, the psychosocial impact of the smile arc and buccal corridor was evaluated in students, 18 - 32 years old, of the Faculty of Dentistry of the UANCV, Juliaca-Peru. The sample consisted of $46.9 \%(n=61)$ male, and $53.1 \%(n=69)$ female, where the minimum age was of 
18 years, the maximum was of 32 years, and the mean was of $21.51 \pm 3.52$ years

\begin{tabular}{lcccc}
\hline \multicolumn{4}{c}{ Gender } \\
& & Male & Female & P value \\
& & $\mathrm{n}(\%)$ & $\mathrm{n}(\%)$ & \\
\hline \multirow{3}{*}{ Smile arc } & Flat & $25(19,2)$ & $38(29,2)$ & \\
& Curve & $17(13,1)$ & $17(13,1)$ & 0,228 \\
& Straight & $19(14,6)$ & $14(10,8)$ & \\
& Wide & $30(23,1)$ & $22(16,9)$ & \\
& Nuccal corridor & $13(10,0)$ & $21(16,2)$ & 0,129 \\
& Null & $18(13,8)$ & $26(20,0)$ & \\
\hline
\end{tabular}

Tabla 1. Prevalence of the smile arc and buccal corridor types, according to gender.

According to the prevalence of the corridor and smile arc types, based on gender, $19.2 \%$ of males and $29.2 \%$ of females had a flat smile arc, yet, $13.1 \%$ of females had a curved smile arc, and $14.6 \%$ of males had a straight smile arc. As for the buccal corridor, $23.1 \%$ of males had a wide corridor and $20.0 \%$ of females had a null corridor. The highest prevalence observed, in both male and female, was the flat smile arc, and the wide and null buccal corridor. There was no significant association between the buccal corridor and sex, or between the smile arc and sex (ChiSquare test $>0.05$ ) (Table 1).

According to gender, the highest value of psychosocial impact was in males, with 6.65 for the curved smile arc and 7.38 for the narrow buccal corridor. In females, the highest psychosocial impact value was of 7.88 for the curved arc, and 7.77 for the null buccal corridor. As analyzed, the highest values of psychosocial impact, in regard to the smile arc and buccal corridor, was presented in female participants (Table 2).

Concerning the average values of the aesthetic preference index of the smile arc and buccal corridor, as reported by gender, males had the highest aesthetic preference value, with 3.76 for the flat smile arc and 4.38 for the narrow buccal corridor. In females, the highest value of aesthetic preference was of 3.84 for the flat smile arc and 3.43 for the null buccal corridor (Table 3 ).

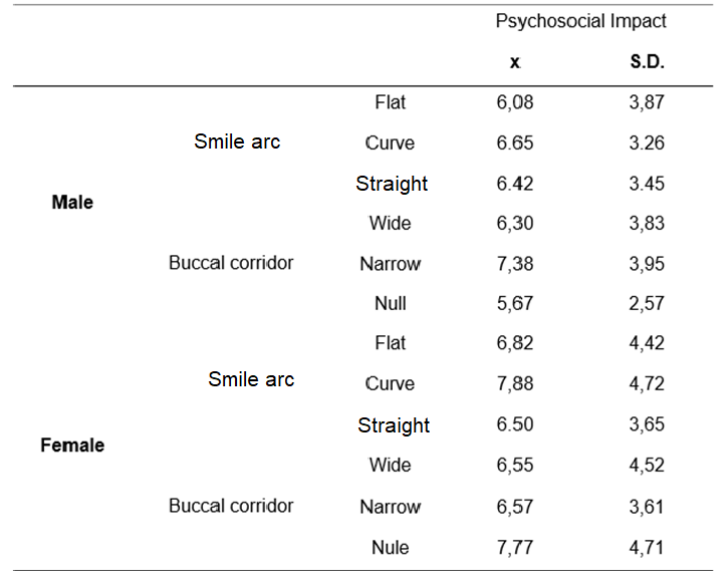

Tabla 2. Mean values of the psychosocial impact of the smile arc and buccal corridor, according to gender.

In relation to the degree of perception and aesthetic preference of the smile, according to gender, males obtained a negative correlation of -0.089 , while females attained a -0.065 ; both coinciding in the pattern of non-correlation. Consequently, no correlation was found between the variables (Table 4).

\begin{tabular}{|c|c|c|c|c|}
\hline & & & \multicolumn{2}{|c|}{ Aesthetic preferences } \\
\hline & & & $\mathrm{x}$ & S.D. \\
\hline \multirow{6}{*}{ Male } & \multirow{4}{*}{ Smile arc } & Flat & 3,76 & 1,83 \\
\hline & & Curve & 3,35 & 2,34 \\
\hline & & Straight & 3,53 & 3,41 \\
\hline & & Wide & 3,83 & 2,39 \\
\hline & \multirow[t]{2}{*}{ Buccal corridor } & Narrow & 4,38 & 2,50 \\
\hline & & Null & 2,56 & 2,53 \\
\hline \multirow{6}{*}{ Female } & \multirow{3}{*}{ Smile arc } & Flat & 3,84 & 3,30 \\
\hline & & Curve & 3,00 & 2,21 \\
\hline & & Straight & 3,00 & 2,57 \\
\hline & \multirow{3}{*}{ Buccal corridor } & Wide & 3,32 & 2,88 \\
\hline & & Narrow & 3,52 & 2,89 \\
\hline & & Null & 3,54 & 3,08 \\
\hline
\end{tabular}

Tabla 3. Mean values of the aesthetic preference index of the smile arc and buccal corridor, according to gender. 


\begin{tabular}{cccc}
\hline & & $\begin{array}{c}\text { Confidence in } \\
\text { their own smile }\end{array}$ & $\begin{array}{c}\text { Awareness of } \\
\text { dental aesthetic }\end{array}$ \\
\hline Male & $\begin{array}{c}\text { Confidence in their } \\
\text { own dental aesthetic } \\
\text { Awareness of } \\
\text { aesthetics } \\
\text { Female }\end{array}$ & $-0,089$ & $-0,089$ \\
& $\begin{array}{c}\text { Confidence in } \\
\text { own dental aesthetic } \\
\text { Awareness of } \\
\text { aesthetics }\end{array}$ & 1 & 1 \\
& $-0,065$ & $-0,065$ \\
\hline
\end{tabular}

Tabla 4. The correlation between the degree of perception and the aesthetic preferences of the smile, according to gender.

\begin{tabular}{lcrrrr}
\hline & \multicolumn{5}{c}{ PIDAQ } \\
& $X$ & SD & Min. & Max. & $P$ value \\
& & & & & \\
Male & 28,66 & 9,71 & 12,00 & 58,00 & \\
Female & 29,52 & 11,31 & 9,00 & 78,00 & 0,753 \\
\hline
\end{tabular}

Tabla 5. The Psychosocial Impact of Dental Aesthetic (PIDAQ) in the studied sample, according to gender.

\begin{tabular}{lrrrr}
\hline & \multicolumn{3}{c}{ PIDAQ } & \\
& $\times$ & SD & Min. & Max. \\
& & & & \\
PIDAQ & 29,11 & 10,55 & 9,00 & 78,00 \\
\hline
\end{tabular}

Tabla 6. The Psychosocial Impact of Dental Aesthetic (PIDAQ) on the studied sample.

In the sample studied by gender, the results demonstrated the Psychosocial Impact of Dental Aesthetics (PIDAQ), with scores of 28.66 for males, and 29.52 for females. Additionally, the minimum value in females was a score of 9 , while the maximum value was a score of 78 . There was no significant difference found between PIDAQ values and gender (Mann-Whitney U test>0.05) (Table 5).

According to the Psychosocial Impact of Dental Aesthetics (PIDAQ), in the studied sample, an average value of $29.11 \pm 10.55$ was obtained; the minimum value was 9.00, and the maximum value was 78.00 (Table 6) .

\section{DISCUSSION}

The psychosocial impact of the buccal corridor and the smile arc has been explored in many previous investigations. However, these generally focused on a single characteristic of smile aesthetics and not investigating the interaction between its elements.11,12 Thus, through the present study, information was obtained on the psychosocial impact and the relationship presented between the buccal corridor and the smile arc on the perception of aesthetics in our population, through the use of a survey. PIDAQ was used, as in previous studies13, to comprehend the psychosocial impact of dental aesthetics on each student.

In this study, the prevalence of three types of buccal corridors were evaluated; narrow, wide and null buccal corridors, as in the study by Parekh et al. ${ }^{14}$ and unlike other studies, such as Moore et al., ${ }^{17}$ Zange et al. ${ }^{17}$ and Loi et al. ${ }^{16}$ whom classified the buccal corridor in percentages. For the smile arc, three types of arcs were used: flat, curve and straight corridors, along with the smile arc configuration, according to gender. When studying the prevalence of the types of corridor and smile arc, according to gender, it was found that the highest prevalent smile arc, in male and female, was the flat type. While, $13.1 \%$ of males presented a curved arc, $10.8 \%$ of females were a straight type. As for the buccal corridor, $23.1 \%$ of males had a wide corridor, and $20.0 \%$ of females had a null corridor. The highest prevalence examined, in both genders, was flat for the smile arch, and broad and null for the buccal corridor. This data shows that no significant association was found between the buccal corridor and gender or between the smile arc and gender (Table 1). This study is one of the first to assess the prevalence of the smile arc and corridor types, based on gender.

When assessing the psychosocial impact of the smile arc and buccal corridor, according to gender, the highest value of psychosocial impact found in the male population was of 6.65 for the curved smile arc, and 7.38 for the narrow corridor, whereas in females, the highest value of psychosocial impact was of 7.88 for the curved arc and 7.77 for the null buccal corridor (Table 2). Research, such as Rappaport et al.,18 demonstrated that orthodontic treatment not only results in an aesthetic improvement, but it also has a significant impact on the psychosocial aspects of patients. In this analysis, the highest values of psychosocial impact were presented by women participants.

Correa displayed, in his study, significant differences between the PIDAQ value achieved before and after an aesthetic treatment (whitening)., ${ }^{13}$ evidencing that there is a change in the psychosocial aspects of the participants in the sample. Thus, it could demonstrate that a positive psychosocial impact is achieved by improving dental 
aesthetics. In this examination, the PIDAQ scores obtained were of 28.66 for males and 29.52 for females. The minimum value in the female gender was a score of 9 , and the maximum value, in that same group, was a score of 78 , with no significant difference between the PIDAQ values and gender (Mann-Whitney U test $>0.05$ ) (Table 5).

Correa also evaluated the social impact that adolescents may experience, due to a subjectively unfavorable dental appearance. ${ }^{13}$ Studies have shown that those who are considered attractive experience more positive social situations and are better qualified by their peers. Bos et al, Tung et al, and Klages et al. demonstrated a direct effect of dental aesthetics on the quality of life, with greater concern for the social aspect of people with poor dental aesthetics. ${ }^{19-22}$ When evaluating the buccal corridor, Moore et al. concluded that ordinary people preferred that a minimum of the buccal corridor (CB $2 \%$ ) be exposed during a smile. ${ }^{15}$ Furthermore, Martin et al. found that orthodontists considered null buccal corridors as most attractive, whereas ordinary people preferred narrow buccal corridors. In this analysis, it was found that in males, the highest aesthetic preference value for the narrow buccal corridor was of 4.38 , while in females, the highest aesthetic preference value for the null corridor was of $3.43 .^{23}$ (Table 3 ).

There are some studies, such as Loi et al. and Roden et al. in which the perception of aesthetics of the smile, in regard to the presence of buccal corridors, was not affected..$^{11,24}$ However, in Espinoza et al., the majority of ordinary people, graduate students and residents of orthodontics, chose a less pleasant smile that presented wide buccal corridor; $8.6 \%$, $15.2 \%$ and $12.4 \% .^{12}$ In this study, the relationship between the degree of perception and the aesthetic preference of the smile was evaluated, according to gender, when judged by dentistry students. The results revealed a negative correlation of - 0.089 in male patients, and -0.065 in female patients; showing a lack of correlation between the variables (table 4).

When evaluating the aesthetic preference index of the buccal corridor, according to gender, the greatest value of aesthetic preference for male, for the narrow buccal corridor, was of 4.38, while for females, the highest aesthetic preference value for the null buccal corridor was of 3.54 (Table 3). Espinoza et al. studied the pleasantness of the smile in ordinary people, graduated students and residents, based on gender. They discovered that for both genders, the smile that was chosen as the most pleasant by ordinary people was the narrow buccal corridor, while graduate students and residents chose the null buccal corridor. ${ }^{12}$ In the present study, the smile with the least preference for male patients was the smile with no buccal corridor (2.56), whereas for female patients, the smile with less preference was the wide buccal corridor. Espinoza et al. determined that the smile chosen as the least pleasant, for male, in the opinion of ordinary people, graduates and residents were smiles with wide buccal corridor. ${ }^{12}$ For females, the least pleasant smile was the wide buccal corridor, unlike a narrow and empty buccal corridor, in the case of residents. Nevertheless, the data shows that there is no difference in the election of the most pleasant smile, regarding the evaluator's gender. Moore et al., found that ordinary people find minimal buccal corridors more pleasant, while considering wide corridors not pleasant. ${ }^{15}$ Contrarily, Zange et al. argued that the presence or absence of loop corridors does not have much influence on smile aesthetics., ${ }^{17}$ and Roden et al. affirmed that the presence of mouth corridors also has no influence on smile aesthetics. ${ }^{24}$

Ultimately, ordinary people, graduates and residents prefer smiles with minimal to null gingival exposure, and minimal or null buccal corridors; considering smiles with wide buccal corridors and gingival exposure of $4 \mathrm{~mm}$ as unattractive smiles. Both, male and female patients, agree that gingival exposure of $+4 \mathrm{~mm}$ is unpleasant, but the pleasure or dislike of the buccal corridor, based on gender, is related to the amount of gingival exposure shown. Thus, the buccal corridor does not have a relevant influence in the perception of the smile.

\section{CONCLUSIONS}

The smile arc and the buccal corridor generate a moderate psychosocial impact on the students, with predominance in the female sex .

CONFLICT OF INTEREST: The authors declare no conflict of interest.

Acknowledgement: The editorial team appreciates the review and grammatical correction in English by Ms. Nicole Gabriela Cordero Astudillo (Dpto. de Investigación, Carrera de Odontología. Universidad Católica de Cuenca).

\section{REFERENCES}

1 Santos N. Original article psychosocial impact of dental esthetics on quality of life in adolescent's association with malocclusion, self-image, and oral health- related issues decide. Angle Orthod. 2009; 79 (6): 452.

2 World Health Organization. The World Oral Healt Report 2003: Continuous Improvement of Oral Health in the21st Century: The Approach of the WHO Global Oral Health Programme. Geneva: WHO; 2003.

3 Chen M, Andersen M, Bares DE, Leclercq M, Little CS. Comparing Oral Health Systems. A second international collaborative study. Geneva: WHO; 1997.

4 Azuma S, Kohzuki M, Saeki S, Tajima M, Igarashi K, Seaware. Beneficial effects of orthodontic treatment on quality 
of life in patients with malocclusion. Tohoku $\mathrm{J}$ Expend. 2008; 214: 39-50.

5 Bernie E, Tasks G, De Oliveira CM, Sheehan A. Impact son daily performances attributed to malocclusions using the condition-specific feature of the Oral Impacts on Daily Performances. Angle Orthodox. 2008; 78: 241-247.

6 Zhang M, McGrath C, Hag U. Who knows more about the impact of malocclusion on children's quality of life, mothers and fathers? Euro J Orthodox. 2007; 29: 180-185.

7 Capúcela, Tratamiento del desdentado total. Buenos Aires: Editorial Mundo; 1987. p. 264-278.

8 Echevarría J, Cuenca E, Fumarola J. El manual de la odontología. Madrid, España: Olivier; 1995.

9 Moreno M, Giménez C. Evaluación de la Calidad de vida Madrid: Siglo XXI; 1996; 1045-1070.

10 Gómez-Vela M, Sabe E. Calidad de vida. Evolución del concepto y su influencia en la investigación y la práctica. Salamanca, España: Universidad de Salamanca; 2007.

11 Loi H, Nakata S, Counts AL. Effects of buccal corridors on smile esthetics in Japanese. Angle Orthod. 2009; 79 (4): 628-33.

12 Espinoza K, Ríos K, Liñan C. Influence of buccal corridor and gingival display in the perception esthetic of the smile. Rev Estomatol Herediana. 2015; 25 (2): 133-144.

13 Correa M. Impacto psicosocial de la estética dental en personas sometidas a blanqueamiento dental. Tesis de Grado. Santiago, Chile: Universidad de Chile; 2015.

14 Parekh SM, Fields HW, Beck M, Rosenstiel S. Attractiveness of variations in the smile arc and buccal corridor space as judged by orthodontists and laymen. Angle Orthod. 2006; 76 (4): 557-63.

15 Moore T, Southard KA, Casko JS, Qian F, Southard TE. Buccal corridors and smile esthetics. Am J Orthod Dentofacial Orthop. 2005; 127 (2): 208-13

16 Loi H, Kang S, Shimomura T, et al. Effects of buccal corridors on smile esthetics in Japanese and Korean orthodontists and orthodontic patients. Am J Orthod Orthop dentofacial. 2012; 142: 459-65.

17 Zange SE, Ramos AL, Cuoghi OA, de Mendonça MR, Suguino R. Perceptions of laypersons and orthodontists regarding the buccal corridor in long- and short-face individuals. Angle Orthod. 2011; 81 (1): 86- 90.

18 Gazit-Rappaport T, Haisraeli-Shalish M, Gazit E. Psychosocial reward of orthodontic treatment in adult patients. European Journal of Orthodontics. 2010; 32: 441-446.

19 Bos A, Hoogstraten J, Prahl-Andersen B. Expectations of treatment and satisfaction with dentofacial appearance in orthodontic patients. Am J Orthod Dentofacial Orthop. 2003; 123: 127-32.

20 Tung AW, Kiyak HA. Psychological influences on the timing of orthodontic treatment. Am J Orthod Dentofacial Orthop. 1998; 113: 29- 39.

21 Klages U, Bruckner A, Zentner A (2004). Dental aesthetics, selfawareness, and oral health-related quality of life in young adults. Eur J Orthod; 26: 507-514.

22 Klages U, Claus N, Wehrbein H, Zentner A. Development of a questionnaire for assessment of the psychosocial impact of dental aesthetics in young adults. European Journal of Orthodontics. 2006; 28: 103-111.

23 Martin AJ, Buschang PH, Boley JC, Taylor RW, McKinney TW. The impact of buccal corridors on smile attractiveness. Eur J Orthod. 2007; 29 (5): 530-7.

24 Roden-Johnson D, Gallerano R, English J. The effects of buccal corridor spaces and arch form on smile esthetics. Am J Orthod Dentofacial Orthop. 2005; 127 (3): 343-50.

Recibido: 26 de junio de 2020

Aceptado: 29 de agosto de 2020 